\title{
Avaliação dos Potenciais Efeitos Adversos em Pacientes em Uso de Isotretinoína oral para o Tratamento de Acne Vulgar: Uma Revisão Bibliográfica
}

\author{
Wesley Graciano de Oliveira Pereira ${ }^{1}$; Rodrigo Santos Damascena ${ }^{2}$
}

\begin{abstract}
Resumo: A acne é uma condição clínica caracterizada como uma inflamação crônica na pele, mais precisamente na unidade polissebácea. O seu tratamento normalmente é realizado com o uso de antimicrobianos, retinóides e agentes abrasivos. A isotretinoína, embora seja um fármaco de eficácia no tratamento da acne, o mesmo pode desenvolver uma série de efeitos adversos principalmente relacionados a alterações bioquímicas, à pele e membranas mucosas. Objetivo: Identificar através de minuciosa pesquisa bibliográfica os potenciais efeitos adversos do tratamento de acne vulgar com a isotretinoína. Metodologia: Este estudo consiste em uma revisão bibliográfica, que permite analisar a literatura, observando e discutindo sobre métodos, resultados e conclusões gerais sobre o tema escolhido, bem como embasar e possibilitar fomento científico para futuras pesquisas relacionadas ao assunto em questão. Resultados e Discussão: Ao final do estudo verificou-se que os indivíduos que faziam o uso da isotretinoína oral como uma terapêutica contra a acne, apresentou as principais reações adversas, queilite, xerodermia, ressecamento das mucosas, fluxo salivar diminuído e que após o término do tratamento essas alterações desvaneciam. Considerações finais: Ainda que a isotretinoína apresente uma série de reações adversas, a mesma possui uma terapia efetiva no tratamento da acne, solucionando mais de $80 \%$ dos casos, desta forma o farmacêutico deve frisar os riscos teratogênicos, posologia, possíveis reações e interações medicamentosas para uma farmacoterapia bem sucedida.
\end{abstract}

Palavras-chave: Acne vulgar, isotretinoína, reação adversa.

\section{Evaluation of Potential Adverse Effects in Patients on Oral Isotretinoin Use for the Treatment of Acne Vulgaris: A Literature Review}

\begin{abstract}
Acne is a clinical condition characterized as a chronic inflammation in the skin, more precisely in the polysbaceous unit. Its treatment is usually carried out with the use of antimicrobials, retinoids and abrasive agents. Although isotretinoin is an effective drug in the treatment of acne, it can develop a number of adverse effects mainly related to biochemical changes to the skin and mucous membranes. Objective: To identify, through potential bibliographic research, the potential adverse effects of acne vulgaris treatment with isotretinoin. Methodology: This study consists of a bibliographical review, which allows analyzing the literature, observing and discussing general methods, results and conclusions on the chosen topic, as well as to base and enable scientific support for future research related to the subject in question. Results and discussion: At the end of the study, it was verified that the individuals who used oral isotretinoin as a therapy against acne, had the main adverse reactions: cheilitis, xeroderma, mucosal dryness, decreased salivary flow and that, after the end of the treatment, these changes faded. Final considerations: Although isotretinoin has a number of adverse reactions, it has an effective therapy in the treatment of acne, solving more than $80 \%$ of cases. So, the pharmacist should emphasize the teratogenic risks, posology, possible reactions and drug interactions for successful pharmacotherapy.
\end{abstract}

Keywords: Acne vulgaris, isotretinoin, adverse reaction.

\footnotetext{
${ }^{1}$ Graduação em Farmácia pela Faculdade Independente do Nordeste - FAINOR, http://www.fainor.com.br, Vitória da Conquista, Bahia, Brasil. Contato: wesley.graciano@yahoo.com.br;

${ }^{2}$ Gaduação em Ciências Farmacêuticas pela Universidade Estadual de Feira de Santana .Especialista em Microbiologia Clínica, Especialista em Saúde Pública com Ênfase em PSF, Especialista em Gestão da Assistência Farmacêutica. Mestrado em Saúde Pública pela Fiocruz. Atualmente é farmacêutico - NASF da Prefeitura Municipal de Vitória da Conquista/BA e Docente da Faculdade Independente do Nordeste (FAINOR).
} 


\section{Introdução}

A acne é uma condição clínica caracterizada como uma inflamação crônica na pele, mais precisamente na unidade polissebácea, de feitio autolimitado e mais frequente em adolescentes (BRITO et.al., 2010). Como sintomas apresenta a formação de comedões, pústulas, cistos, e caso evolua desenvolve-se um processo inflamatório de maior intensidade, podendo desenvolver pústulas, e abscesso (SILVA et. al., 2014).

O tratamento para a acne normalmente é realizado com o uso de antimicrobianos, retinóides (como a isotretinoína) e agentes abrasivos (PIANA; CANTO, 2010). A isotretinoÍna é um composto derivado do retinol, mais comumente conhecida como vitamina A utilizada para o tratamento da acne severa na qual sua ação possui comprovadamente alta eficácia (CAJUEIRO;LIMA;PARTATA, 2014).

Embora seja um fármaco de eficácia excelente, o mesmo desenvolve efeitos adversos substanciais, que na maioria das vezes dificulta o término do tratamento. Os indivíduos que fazem o uso da isotretinoína oral podem apresentar uma serie de efeitos adversos principalmente relacionados a alterações bioquímicas, à pele, membranas mucosas, sistema nervoso, hematopoiético, músculo-esquelético, gastrintestinal, cardiorrespiratório e genitourinário. Além de todas essas reações, a isotretinoína possui efeito teratogênico sendo contraindicado para o uso em gestantes (DINIZ et.al., 2002).

Considerando o uso crescente da isotretinoína para o tratamento da acne bem como os efeitos adversos advindos com essa terapêutica ser de grande preocupação na conduta terapêutica dos pacientes que utilizam tal fármaco, o objetivo do trabalho foi identificar através de minuciosa pesquisa bibliográfica os potenciais efeitos adversos do tratamento de acne vulgar com a isotretinoína. 


\section{Referencial Teórico}

\section{Isotretinoína e Caracteristicas Estruturais}

A isotretinoína ou ácido 13-cis-retinóico ((figura 1), é uma substância pertencente a classe dos retinóides, também conhecidos como derivados da vitamina A. O termo retinóides costuma ser empregado a essa classe de compostos, cuja sua estrutura química consiste em quatro grupos isoprenóides ligados de modo cabeça-cauda. Essa formação possui um anel não aromático de seis átomos de carbono com uma cadeia lateral poliprenóide, que é ter minada com um grupo funcional formado de carbono e oxigênio, na maioria das vezes (DINIZ et. al, 2002).

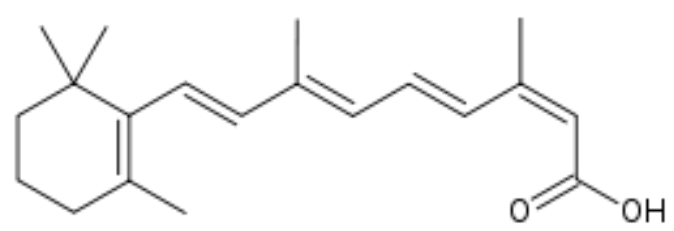

Figura 1. Estrutura química do Ácido 13-cis-retinóico.Fonte: Wikipedia.

\section{Caracteristicas Farmacológicas e Farmacocinéticas}

\section{Farmacocinética}

Segundo Cajueiro, Lima e Partata (2014), as concentrações plasmáticas de isotretinoína após a administração por via oral podem ser atingidas em cerca de duas a quatro horas. Tal fármaco é melhor absorvido no trato gastrointestinal quando há a presença de alimento, promovendo o retardo do esvaziamento gástrico e aumentando o tempo de permanência da droga no organismo.

A isotretinoína é metabolizada pelo processo de oxidação através das enzimas do citocromo P450 presentes na parede do estômago, originando três metabólitos: a 4-oxoisotretinoína, tretinoína e 4-oxo-tretinoína, que se acumula no sangue a partir de seguidas administrações. Ela é excretada pela bile, após passar pela conjugação com o ácido 
glicurônico. Os outros metabólitos são lentamente depositados no plasma e possui meia-vida de eliminação de 25 horas. A isotretinóina tem tempo de meia vida de 7 a 39 horas, estabelecido pelas administrações repetidas e apresenta sua excreção por via urinária (CAJUEIRO; LIMA; PARTATA, 2014).

\section{Mecanismo de Ação}

A isotreinoína age como uma espécie de hormônio e desenrola sua atividade biológica após se ligar e ativar os receptores do ácido retinóico (RAR) e os receptores retinóides X (RXR). Esse retinóide se alia aos fatores de transcrição e complexo ligante-receptor que se une a regiões promotoras dos genes-alvo promovendo a regulação de sua expressão, induzindo ou suprimindo a transcrição gênica. O RNA mensageiro já transcrito passa para o citoplasma e no ribossomo induz a síntese do material proteico que regula a proliferação, diferenciação celular, a inflamação e o funcionamento das glândulas sebáceas (BORGES et. al., 2011).

\section{Acne: Conceito e Epidemiologia}

A acne é uma patologia de ordem hormonal e genética caracterizada pela inflamação dos folículos polissebáceos da face, das costas e tórax. Normalmente ocorre durante a puberdade quando a estimulação androgênica promove hiperprodução de sebo com hiperqueratinização folicular, colonização pelo Propionibacterium acnes e inflamação local. É uma doença auto limitada, de localização pilossebácea, que apresenta diversas intensidades, variando de cistos pilossebásseos dilatados que contêm sebo, epitélio queratinizado, bactérias e leveduras, às formas mais graves que formam nódulos e fístulas com intensa reação inflamatória (JÚNIOR et. al., 2009; SILVA et. al, 2014).

A acne pode ser classificada quanto a sua gravidade em dois tipos: acne inflamatória e não inflamatória, embora os dois tipos possam coexistir em um único paciente. Clinicamente, a acne pode ser separadas em quatro níveis de classificação 
No Brasil, a acne é mais comum dos em adolescentes dos 14 aos 17 anos, mais incidente na população feminina, sendo mais grave nos homens e mais persistente nas mulheres (DINIZ et. al., 2014).

\section{Fisiopatologia da Acne}

A unidade polissebácea na pele normal é constituída por glândulas sebáceas multilobulares, pelo rudimentar e canal folicular envolto de um epitélio escamoso estratificado. O desenvolvimento dessas unidades é regulado por hormônios androgênicos e vários outros fatores biológicos. Os hormônios relacionados com a patogênese da acne são a dehidrotestosterona e testosterona, responsáveis por controlar a atividade das glândulas sebáceas (DINIZ et. al., 2014).

A unidade polissebácea secreta uma substância denominada de sebo, composta por ácidos graxos, triglicerídeos e resíduos de células adiposas cuja função é lubrificar os pelos e proteger a pele do ataque de microorganismos. Entretanto, se há um excesso de sebo produzido pela glândula provocar uma oclusão na região do infidíbulo da unidade, pode ocorrer a formação de um microcomedão, precursor de todas as lesões acnéicas. Tais lesões também estão associadas a bactéria Propionibacterium acnes, que se alojam na glândula sebácea e passa a utilizar os triglicerídeos por ação enzimática, liberando substancias irritantes que atuam como quimiotáticos para as células de defesa do organismo, ocasionando pústulas, pápulas, nódulos e cistos inflamatórios (DINIZ et. al., 2014).

\section{Efeitos adversos associados ao uso de Isotretinoína Oral}

Os efeitos adversos associados ao tratamento através de isotretinoína são divididos em duas classes: efeitos mucocutâneos e efeitos tóxicos sistêmicos. Normalmente, pacientes que usam isotretinoína oral apresentam ressecamento e fissuras nos lábios, pele e mucosas em vista da diminuição da produção de sebo. Também há a redução da espessura do estrato córneo que 
provoca fotossensibilidade, blefaroconjuntivite; também é observado prurido, descamação da pele e dermatite (BRITO et. al, 2010).

Efeitos adversos a nível sistêmico podem atingir os ossos (dor óssea), os músculos, tireoide, rins, olhos, ouvidos e trato gastrointestinal e alterações neuropsíquicas. Também são notadas alterações laboratoriais em função da toxicidade hepática, hematológica e alterações no colesterol e triglicerídeos (BRITO et. al, 2010).

A isotretinoína é um fármaco que apresenta risco para gestantes, pois, demonstra ação teratogênica, principalmente durante o primeiro trimestre de gravidez. Por isso, esse medicamento só é prescrito quando estiver excluída a possibilidade de gravidez, sendo essa condição um fator de contraindicação para o seu uso (BORGES et. al., 2011).

\section{Procedimento Metodológico}

Para a elaboração do artigo foi adotada a metodologia de revisão bibliográfica, que consiste em analisar amplamente a literatura observando e discutindo sobre métodos, resultados e conclusões gerais sobre o tema escolhido para pesquisa, bem como embasar e possibilitar fomento científico para futuras pesquisas relacionadas ao assunto em questão (MINAYO, 2007).

Após a definição do tema, do tipo de pesquisa a ser realizado, foi preparada a seguinte pergunta norteadora: Quais os reações adversas mais prevalentes e os riscos associados ao uso de isotretinoína oral para o tratamento de acne?

Foi realizado o levantamento bibliográfico de artigos científicos, do ano de 2000 a 2017 através da pesquisa nas bases de dados eletrônicas: Literatura Latino-Americana e do Caribe em Ciências da Saúde (LILACS), Scientific Eletronic Library Online (SCIELO), Biblioteca Virtual em Saúde (BVS), Pubmed e Medline. Durante a pesquisa, foram utilizados os seguintes descritores segundo o DeCS: acne vulgar, isotretinoína, reação adversa.

Desta forma, buscaram-se artigos que respondessem a questão da revisão adotando critérios de inclusão e exclusão. Como critérios de inclusão foram adotados os seguintes: relevância ao tema, atualidade das informações contidas no artigo e artigos relacionados com o uso de isotretinoína para o tratamento de acne e os as reações adversas apresentadas 
indexadas nas bases de dados LILACS, BVS, Scielo, Pubmed e Medline. Os critérios de exclusão foram: artigos antigos anteriores ao ano de 2000 e artigos não relacionados com os descritores em saúde utilizados. Após a análise dos artigos através da minuciosa leitura, foram selecionados cinco artigos para compor a revisão de literatura.

\section{Resultados e Discussão}

Dentre os artigos incluídos na revisão, dois foram elaborados por dermatologistas, seguido de dois acadêmicos de farmácia, um de odontologia e executados com pacientes que fazem o uso da isotretinoína oral, incluindo as bases científicas. Os estudos encontrados condizentes aos aspectos da presente revisão foram 13 e cinco aproveitados para proceder à pesquisa.

Na tabela 1 apresenta informações sobre o título, periódico, país de publicação e ano dos artigos incluídos nesta revisão.

Tabela 1: Informações dos artigos incluídos na revisão bibliográfica.

\begin{tabular}{c|c|c|c|c}
\hline Título do Artigo & Periódico & $\begin{array}{c}\text { País de } \\
\text { publicação }\end{array}$ & Idioma & Ano \\
\hline $\begin{array}{c}\text { Avaliação do uso da isotretinoína } \\
\text { pelos pacientes atendidos na } \\
\text { farmácia de medicamentos } \\
\text { excepcionais do município de } \\
\text { Viçosa-MG. }\end{array}$ & $\begin{array}{c}\text { Anais VI SIMPAC, v.6, n.1, } \\
\text { p.197-202, 2014. }\end{array}$ & Brasil & Português & 2014 \\
\hline $\begin{array}{c}\text { Avaliação dos efeitos adversos } \\
\text { clínicos e alterações laboratoriais } \\
\text { em pacientes com acne vulgar } \\
\text { tratados com isotretinoína oral. }\end{array}$ & $\begin{array}{c}\text { An Bras Dermatol. } \\
2010 ; 85(3): 331-7 .\end{array}$ & Brasil & Português & 2010 \\
\hline $\begin{array}{c}\text { Efeito da isotretinoína na } \\
\text { xerostomia, ph e fluxo salivar. }\end{array}$ & $\begin{array}{c}\text { J Health Sci 2016;18(1):13- } \\
17 .\end{array}$ & Brasil & Português & 2016 \\
\hline $\begin{array}{c}\text { Evidências sobre o tratamento da } \\
\text { acne. }\end{array}$ & $\begin{array}{c}\text { Diagn Tratamento. } \\
2013 ; 18(1): 10-4 .\end{array}$ & Brasil & Português & 2013 \\
\hline $\begin{array}{c}\text { Atenção farmacêutica em } \\
\text { dermatologia: fármacos e } \\
\text { Antiacneicos. }\end{array}$ & $\begin{array}{c}\text { Saúde (Santa Maria), v.36, } \\
\text { n.2, p. 3954, } \\
\text { jul./dez. 2010. }\end{array}$ & Brasil & Português & 2010 \\
\hline
\end{tabular}


$\mathrm{Na}$ tabela 2 apresenta a síntese dos artigos integrados com as seguintes informações, objetivo, metodologia, resultados e potenciais efeitos adversos que na maioria dos estudos apresentaram xerostomia e ressecamento das mucosas como os efeitos adversos mais comuns.

Tabela 2: Caracterização da síntese dos artigos incluídos na revisão bibliográfica.

\begin{tabular}{|c|c|c|c|c|}
\hline & Objetivo & Metodologia & Resultados & $\begin{array}{l}\text { Potenciais efeitos } \\
\text { adversos da isotretinoína } \\
\text { oral para o tratamento } \\
\text { de acne severa }\end{array}$ \\
\hline $\begin{array}{l}\mathbf{A} \\
\mathbf{R} \\
\mathbf{T} \\
\mathbf{I} \\
\mathbf{G} \\
\mathbf{O}\end{array}$ & $\begin{array}{l}\text { Avaliar o uso da } \\
\text { isotretinoína oral, } \\
\text { principalmente } \\
\text { quanto à } \\
\text { apresentação dos } \\
\text { efeitos adversos. }\end{array}$ & $\begin{array}{l}\text { Estudo de caráter } \\
\text { descritivo e } \\
\text { exploratório, uma vez } \\
\text { que visa descrever as } \\
\text { características de } \\
\text { determinada população } \\
\text { e proporcionar maior } \\
\text { familiaridade com o } \\
\text { problema, com vistas a } \\
\text { torná-lo explícito ou a } \\
\text { construir hipóteses. }\end{array}$ & $\begin{array}{l}\text { Os pacientes que estavam } \\
\text { administrando a isotretinoína há } \\
\text { mais de seis meses relataram } \\
\text { apresentar os efeitos adversos } \\
\text { cutâneos mucosos e não } \\
\text { evidenciar os sistêmicos, a } \\
\text { queilite e a xerodermia foram os } \\
\text { predominantes, o ressecamento } \\
\text { das mucosas foi à segunda opção } \\
\text { prevalente. }\end{array}$ & $\begin{array}{l}\text { Os autores evidenciaram que os } \\
\text { efeitos adversos sistêmicos são } \\
\text { pouco frequentes, e os efeitos } \\
\text { adversos mais comuns são a } \\
\text { queilite, a xerodermia e o } \\
\text { ressecamento das mucosas. }\end{array}$ \\
\hline $\begin{array}{l}\mathbf{A} \\
\mathbf{R} \\
\mathbf{T} \\
\mathbf{I} \\
\mathbf{G} \\
\mathbf{O}\end{array}$ & $\begin{array}{l}\text { Avaliar a } \\
\text { tolerabilidade da } \\
\text { isotretinoína oral, } \\
\text { com atenção, no } \\
\text { metabolismo } \\
\text { lipídico, função } \\
\text { hepática e reações } \\
\text { adversas clínicas. }\end{array}$ & $\begin{array}{l}\text { Trata-se de um estudo } \\
\text { de série de casos, no } \\
\text { qual foram incluídos } \\
150 \text { pacientes, com } \\
\text { diagnóstico clínico de } \\
\text { acne, perante os quais } \\
\text { foram submetidos a } \\
\text { tratamento com } \\
\text { isotretinoína oral. }\end{array}$ & $\begin{array}{l}\text { Os efeitos colaterais cutâneos } \\
\text { mucosos da isotretinoína, queilite } \\
\text { foi o mais frequente, seguido de } \\
\text { xerodermia e ressecamento de } \\
\text { mucosas, }(32 \%) \text { da população } \\
\text { apresentaram blefar conjuntivite, } \\
(20,7 \%) \text { descamação palmo } \\
\text { plantar, }(22,7 \%) \text { alopecia e } \\
\text { fragilidade ungueal em ( } 25,3 \%) \\
\text { dos casos, houve piora inicial } \\
\text { importante do quadro acneico } \\
\text { (flare up) em (6\%) dos pacientes. } \\
\text { Os efeitos clínicos sistêmicos } \\
\text { foram menos comuns, a dor } \\
\text { osteomuscular foi o mais } \\
\text { frequente, seguido de cefaleia e } \\
\text { queixas auditivas. }\end{array}$ & $\begin{array}{l}\text { Os autores elucidam que a } \\
\text { isotretinoína é uma droga } \\
\text { segura e com efeitos colaterais } \\
\text { laboratoriais bem tolerados que } \\
\text { o excelente resultado em } \\
\text { pacientes tratados com acne } \\
\text { moderada e severa supera as } \\
\text { alterações bioquímicas e } \\
\text { hematológicas a que estão } \\
\text { expostos os pacientes tratados. }\end{array}$ \\
\hline $\begin{array}{l}\mathbf{A} \\
\mathbf{R} \\
\mathbf{T} \\
\mathbf{I} \\
\mathbf{G} \\
\mathbf{O}\end{array}$ & $\begin{array}{l}\text { Avaliar a influência } \\
\text { da isotretinoína no } \\
\text { grau de xerostomia, } \\
\text { pH e fluxo salivar. }\end{array}$ & $\begin{array}{l}\text { A pesquisa consiste em } \\
\text { um estudo analítico } \\
\text { observacional } \\
\text { transversal. }\end{array}$ & $\begin{array}{l}\text { Os resultados obtidos } \\
\text { demonstraram um aumento no } \\
\text { grau da xerostomia nos } \\
\text { indivíduos acneicos que fazem o } \\
\text { uso da isotretinoína do que nos } \\
\text { indivíduos que já fizeram o uso } \\
\text { deste medicamento e os não } \\
\text { acneicos saudáveis. As principais } \\
\text { regiões que sofreram } \\
\text { ressecamento pelo uso da } \\
\text { isotretinoína, foram os lábios, a } \\
\text { pele da face, os olhos e a mucosa }\end{array}$ & $\begin{array}{l}\text { Os autores salientaram que o } \\
\text { fluxo salivar apresentou } \\
\text { diminuição nos indivíduos que } \\
\text { fazem o uso da isotretinoína } \\
\text { bem como o aumento da } \\
\text { xerostomia. }\end{array}$ \\
\hline
\end{tabular}




\begin{tabular}{|c|c|c|c|c|}
\hline & & & $\begin{array}{l}\text { do nariz ressecado. O ph da saliva } \\
\text { apresentou uma ligeira } \\
\text { diminuição com o uso da } \\
\text { isotretinoína, porém não foi } \\
\text { significante. }\end{array}$ & \\
\hline $\begin{array}{l}\mathbf{A} \\
\mathbf{R} \\
\mathbf{T} \\
\mathbf{I} \\
\mathbf{G} \\
\mathbf{O}\end{array}$ & $\begin{array}{l}\text { O objetivo desta } \\
\text { revisão narrativa é } \\
\text { apresentar o que há } \\
\text { de mais recente em } \\
\text { termos de evidências } \\
\text { científicas de boa } \\
\text { qualidade no } \\
\text { tratamento tópico e } \\
\text { sistêmico da acne } \\
\text { vulgar. }\end{array}$ & $\begin{array}{l}\text { Para a realização do } \\
\text { estudo foi feito uma } \\
\text { busca sistematizada nas } \\
\text { principais bases de } \\
\text { dados por estudos } \\
\text { relacionados ao } \\
\text { tratamento da acne no } \\
\text { período compreendido } \\
\text { entre os anos de } 2001 \text { e } \\
\text { 2011, utilizando } \\
\text { descritores em saúde } \\
\text { ou termos relacionados } \\
\text { ao assunto em questão. }\end{array}$ & $\begin{array}{l}\text { A isotretinoína oral atua sobre } \\
\text { todos os mecanismos } \\
\text { etiopatogênicos relacionados à } \\
\text { acne vulgar, efetiva e promove a } \\
\text { cura clínica em } 85 \% \text { dos casos, a } \\
\text { isotretinoína está indicada em } \\
\text { casos graves, resistentes às } \\
\text { demais terapias, e pacientes com } \\
\text { tendência a formação de } \\
\text { cicatrizes (THIBOUTOT, D. et } \\
\text { al, 2009; NAST, A. et al, 2010). } \\
\text { Ainda se fazem necessárias } \\
\text { evidências científicas acerca do } \\
\text { uso precoce em casos moderados, } \\
\text { os efeitos adversos graves } \\
\text { relacionados à isotretinoína, entre } \\
\text { eles teratogenicidade e o possível } \\
\text { risco de surgimento de doenças } \\
\text { inflamatórias intestinais, } \\
\text { depressão e suicídio } \\
\text { (BERNSTEIN, C.N. et al, 2010). }\end{array}$ & $\begin{array}{l}\text { Os estudiosos evidenciaram que } \\
\text { apesar de um grande número de } \\
\text { produtos comerciais para o } \\
\text { tratamento da acne com } \\
\text { diferentes combinações de } \\
\text { drogas, não existem estudos } \\
\text { comparativos suficientes para } \\
\text { gerar evidência de boa } \\
\text { qualidade em relação ao arsenal } \\
\text { terapêutico da acne. }\end{array}$ \\
\hline $\begin{array}{l}\mathbf{A} \\
\mathbf{R} \\
\mathbf{T} \\
\mathbf{I} \\
\mathbf{G} \\
\mathbf{O}\end{array}$ & $\begin{array}{l}\text { Promover subsídios } \\
\text { aos profissionais } \\
\text { farmacêuticos } \\
\text { para a realização da } \\
\text { atenção farmacêutica } \\
\text { na área } \\
\text { dermatológica, } \\
\text { especificamente } \\
\text { quanto ao } \\
\text { uso de fármacos } \\
\text { antiacneicos. }\end{array}$ & $\begin{array}{l}\text { Esta pesquisa foi } \\
\text { realizada através da } \\
\text { análise de artigos } \\
\text { científicos disponíveis } \\
\text { principalmente nas } \\
\text { bases de dados do } \\
\text { Scopus e } \\
\text { ScienceDirect. }\end{array}$ & $\begin{array}{l}\text { A isotretinoína derivado da } \\
\text { vitamina A, um revolucionário } \\
\text { fármaco que age em mecanismos } \\
\text { de patogênese da acne moderada } \\
\text { á grave diminuindo a } \\
\text { proliferação. } \\
\text { É contra indicada em mulheres } \\
\text { grávidas, insuficiência hepática, } \\
\text { hipervitaminose A, } \\
\text { hiperlipidemias e antecedentes } \\
\text { depressivos. Os principais efeitos } \\
\text { adversos são eritema, } \\
\text { ressecamento da pele, dermatites } \\
\text { faciais, alterações de humor, } \\
\text { aumento dos níveis sanguíneos de } \\
\text { colesterol total e triglicerídeos, e } \\
\text { teratogenicidade. }\end{array}$ & $\begin{array}{l}\text { Os autores destacaram que a } \\
\text { acne por ser uma doença } \\
\text { frequente que acomete } \\
\text { principalmente os jovens com } \\
\text { transtornos emocionais, deve se } \\
\text { atentar não somente aos } \\
\text { tratamentos, como também o } \\
\text { nível de estresse gerado. Vale } \\
\text { salientar que existe uma ampla } \\
\text { variedade de medicamentos } \\
\text { empregados no tratamento da } \\
\text { acne, alguns com potenciais } \\
\text { toxicidade, para uma } \\
\text { farmacoterapia bem sucedida e } \\
\text { evitar a automedicação a } \\
\text { atenção farmacêutica é } \\
\text { imprescindível para um } \\
\text { atendimento personalizado e } \\
\text { cientificamente correto. }\end{array}$ \\
\hline
\end{tabular}


Os estudos 1, 2 e 3 são de abordagem descritiva e utilizaram-se do método de entrevista nos quais foram adaptados questionários aos pacientes abordados para avaliar o uso da isotretinoína oral no tratamento da acne e seus efeitos adversos.

Os estudos 4 e 5 foram construídos através de buscas sistematizadas das principais bases de dados científicos relacionados ao tratamento da acne.

No estudo 1 a coleta de dados foi realizada em um período de um mês em uma farmácia de medicamentos excepcionais no estado de Minas Gerais, foram abordados pacientes portadores de acne severa, os mesmos foram submetidos ao tratamento para avaliação do uso da isotretinoína oral, os indivíduos entrevistados sendo a maioria destes utilizavam a isotretinoína oral de um a seis meses e apresentaram queilite, xerodermia e ressecamento das mucosas.

Tal achado corrobora com os estudos de Brito et al (2010), que avaliou os efeitos colaterais cutâneos mucosos da isotretinoína, 94\% da população apresentaram queilite seguido de xerodermia.

No artigo 2 foram incluídos 150 pacientes sendo maioria do sexo masculino com diagnóstico de acne, sujeitos ao tratamento com isotretinoína oral, o acompanhamento ocorreu em Recife em um ambulatório de dermatologia. Periodicamente, os pacientes eram examinados e realizavam avaliações clínicas e laboratoriais antes e após o tratamento, a dose do medicamento foi ajustada de acordo com peso corporal e evolução clínica.

Destes 150 pacientes em tratamento com a isotretinoína, a maioria apresentaram queilite, xerodermia e uma minoria relataram alopecia, granuloma piogênico, piodermites, furúnculos e foliculite como efeitos colaterais. Foram ainda avaliados os efeitos clínicos sistêmicos sendo o mais frequente a dor osteomolecular e menor frequência queixas auditivas.

Semelhantemente aos estudos de Sampaio (2001), os efeitos colaterais mucocutâneos em $94 \%$ dos indivíduos apresentaram queilite, a xerodermia e ressecamento das mucosas ocorreram em $47 \%$ dos casos avaliados.

Na pesquisa 3, no qual realizou um estudo para avaliar os efeitos da isotretinoína na xerostomia, ph e fluxo salivar em uma farmácia no estado do Espirito Santo, foram divididos grupos de indivíduos não acneicos saudáveis, acneicos que nunca utilizaram a isotretinoína oral para o tratamento, indivíduos acneicos em uso da isotretinoína e aqueles que já havia concluído o tratamento de acne com o uso deste medicamento, estes participantes foram submetidos a 
anamnese para avaliar os dados referente a identificação, histórico ondológico e médico. Para o teste de análise, foi realizada a coleta da saliva de todos os participantes, os mesmos foram orientados não ingerir alimentos sólidos e líquidos por 1 hora e 30 minutos antes do exame.

Nos resultados obtidos o grupo que estava fazendo o tratamento com isotretinoína apresentou grau de xerostomia maior e o fluxo salivar menor, o grupo que havia concluído o tratamento apresentou grau de xerostomia menor referente ao que ainda estava sob uso deste medicamento.

Gomes et al (2009), relatou em seus estudos que todos os indivíduos que utilizaram isotretinoína na dose de $0,5-0,7 \mathrm{mg} / \mathrm{kg}$ dia, por um período de um mês apresentaram xerostomia.

Ao avaliar evidências sobre o tratamento da acne no estudo 4, foi realizado uma busca nas principais bases de dados relacionados ao tratamento da acne entre 2001 a 2011, foi utilizados descritores em saúde sobre a terapêutica tópica da acne vulgar.

Nos achados, foram citados as terapêuticas tópicas e sistêmicas para acne vulgar, dentre os tópicos o peróxido de benzoila (PB), é utilizado no tratamento da acne moderada a grave, podendo ser administrado em monoterapia (THIBOUTOT D. et al. 2009; NAST, A. et al, 2010). Os retinoides, que são derivados da vitamina A previnem a formação de comedões normalizando a descamação do epitélio folicular (NAST, A. et al, 2010). Os antibióticos clindamicina e a eritromicina também são indicados por suspender a proliferação de bactérias e reduzir a inflamação (WILLIAMS, H.C.; DELLAVALLE, R.P.; GARNER, S. 2012; HAIDER, A.; SHAW, J.C. 2004). Já as terapêuticas sistêmicas, apenas a isotretinoína oral atua sobre todos os mecanismos etiopatogênicos relacionados à acne vulgar, é efetiva e promove a cura clínica em mais de $80 \%$, ela está indicada nos casos mais graves e resistentes às demais terapias, toda via se faz necessários mais evidências científicas sobre os efeitos adversos deste medicamento, entre eles a teratogenicidade e doenças inflamatórias (THIBOUTOT, D. et al, 2009; NAST, A. et al 2010 ).

No tocante à atenção farmacêutica em dermatologia sobre os fármacos e antiacneicos, o estudo 5, como anteriormente, foi realizado através da análise de artigos científicos disponíveis nas bases de dados principalmente, Scopus e ScienceDirect, para uma melhor organização das informações, foram adaptadas tabelas para orientação farmacêutica e mini bulas que continha apenas informações relevantes aos pacientes como, uso correto do 
medicamento, contraindicações, possíveis reações adversas e interações medicamentosas, que serão extremamente importantes para garantir uma terapia segura e eficaz.

Nos resultados foram discutidos que, o tratamento da acne deve ser ser realizado por antimicrobianos retinóides e agentes abrasivos. Em preparações tópicas, o ácido azeláico é uma boa alternativa para o tratamento de acne leve a moderada ou com hiperpigmentação pós inflamatória ( HERRA, C. G. 2010; FAVANO, A.; GODOY, F. Z.; ZANETTE, K.; CAETANO 2007). Outros terapêuticos foram citados no tratamento da acne vulgar, peróxido de benzoila, tretaciclina, eritromicina, clindamincina e retinóides apresentados anteriormente. Vale ressaltar que os agentes abrasivos como enxofre e ácido salicílico provocam desmacação, esfoliação e consequentemente, irritação e nem todos os irritantes tópicos diminuem os comedões ou impedem a formação de lesões (GUZZO, C.A.; LAZARUS, G.; WETH, V.P. 1996; HERRA, C. G. 2010). Quanto à isotretinoína e seus principais efeitos adversos os autores mencionaram, eritema, ressecamento da pele dermatites faciais, alterações de humor, teratogenicidade o que implica o impedimento da gravidez e aumento dos níveis de colesterol total e triglicerídeos (NGUYEN, R.; SU, J. 2011; MARTINDALE, 2006).

\section{Considerações Finais}

A partir do estudo realizado para avaliar os potenciais efeitos adversos em pacientes com uso da isotretinoína oral no tratamento da acne severa, pôde-se concluir que as reações adversas corriqueiras são a queilite, xerodermia e ressecamento das mucosas, bem como as alterações sistêmicas ocorre em minoria dos indivíduos que fazem uso deste medicamento.

Embora apresente essas reações, a isotretinoína possui uma terapia efetiva contra a acne, o seu resultado supera as alterações bioquímicas e laboratoriais que os pacientes estão suscetíveis, podendo ser bem toleradas. Salientar os efeitos teratogênicos, posologia, possíveis reações adversas e interações medicamentosas devem ser indispensáveis ao farmacêutico, dessa forma, poderá consolidar uma atuação profissional satisfatória e tratar adequadamente os pacientes que lhes forem encaminhados. 


\section{Referências}

BERNSTEIN, C.N.; NUGENT, Z.; LONGOBARDI, T.; BLANCHARD, J.F. Isotretinoin is not associated with inflammatory bowel disease: a population-based case-control study. American Journal of Gastroenterology, v.104, n.11, p. 2774-8, 2009.

BORGES et. al. Avaliação laboratorial do perfil lipídico e testes de lesão hepatocelular em pacientes com acne vulgar sob o uso de isotretinoína oral. São Paulo: Rev Bras Clin Med. 2011 nov-dez; 9 (6): 397-402.

BRITO et. al. Avaliação dos efeitos adversos clínicos e alterações laboratoriais em pacientes com acne vulgar tratados com isotretinoína oral. An Bras Dermatolol. 2010; 85 (3): 331-337 p.

CAJUEIRO et. al. Isotretinoína e suas propriedades farmacológicas. Araguaína: Revista Cientifica do ITPAC. 2014 7v., n.1, Pub.4. 16 p.

COSTA, Caroline Sousa; BAGATIN, Ediléia. Evidências sobre o tratamento da acne. Diagn Tratamento, São Paulo, v. 8, n. 1, p.10-14, jan. 2013.

DINIZ et al. Isotretinoína: perfis farmacológico, farmacocinético e analítico. Revista Brasileira de Ciencias Farmacêuticas. v.38, n.4, out/dez, 2002.

DINIZ et. al. Terapia Retinóide na Acne Vulgar. Revisa Eletrônica de Farmácia. Vol.XI (3), 80-101, 2014, 22 p.

FAVANO, A.; GODOY, F.Z.; ZANETTE, K.; CAETANO, B.P.R. Guia de Remédios 8 nd ed. São Paulo (SP): Editora Escala; 2007.

GOMES, S.G.F.; CUSTÓDIO, W.; CURY, A.A.; GARCIA, R.C. Effect of salivary flow rate on masticatory efficiency. Journal of Prosthodonticst, v. 22 p.168-72. 2009

GUZZO, C.A.; LAZARUS, G.; WETH, V.P. Dermatologia. In: Goodman \& Gilman As bases farmacológicas da terapêutica. 9 nd ed. Rio de Janeiro(RJ): Mc Graw Hill Interamericana Editores, p.118411951996.

HAIDER, A. SHAW, J.C. Treatment of acne vulgaris. JAMA, v. 292 n.6 p. 726-35. 2004

HERRA, C.G. El acne y su tratamiento. Centro nacional de información de medicamentos. Universidad de Costa Rica. Costa Rica 2003. [periódico na Internet]. 2010 dez. Disponível em http:// www.sibdi.bldt.ucr.ac.cr/CIMED/

MARTINDALE. Guía completa de consulta fármacoterapéutica 2nd ed. Barcelona: Pharma Editores; 2006. 
MINAYO, M. C. de S. O desafio do conhecimento. 10. ed. São Paulo: HUCITEC, 2007. NAST, A.; BAYERL, C.; BORELLI, C. et al. S2k-leitlinie zur therapie der akne S2kguideline for therapy of acne. Journal of the German Society of Dermatology, v.8, n. 2, p. $59,2010$.

NGUYEN, R.; SU, J. Treatment of acne vulgaris. Paediatrics and Child Health, v. 21 n.3 p. $119125,2011$.

PIANA, Mariana; CANTO, Gisele Scotti do. Atenção Farmacêutica em Dermatologia: Fármacos e Antiacnéicos. Saúde (Santa Maria), v.36, 2010, 39-54p.

SAMPAIO, Sebastião de Almeida Prado; BAGATIN, Ediléia. Experiência de 65 anos no tratamento da acne e de 26 anos com isotretinoína oral. An Bras Dermatol,SÃo, v. 83, n. 4, p.361-367, jul. 2008.

SILVA JÚNIOR, Edilson Dantas da et al. Isotretinoína no tratamento da acne: riscos $\mathrm{x}$ benefícios. Rev. Bras.farm, Paraíba, v. 90, n. 3, p.186-189, jul. 2009.

SILVA, Lairicy Neves da et al. Acompanhamento farmacoterapêutico do uso da isotretinoina: um estudo de caso. Revista Faculdade Montes Belos (fmb), Montes Belos, v. 7, n. 1, p.121135, jan. 2014.

THIBOUTOT, D.; GOLLNICK, H.; BETTOLI, V., et al. New insights into the management of acne: an update from the Global Alliance to Improve Outcomes in Acne group. Journal of the American Academy of Dermatology, v. 60, n. 5, p. 50, 2009.

VAZ, Ana Lúcia. Acne vulgar: bases para o seu tratamento. Rev Port Clin Geral, Lisboa, v. 18 , n. 1, p.561-570, jan. 2003.

WILLIAMS, H.C.; DELLAVALLE, R.P.; GARNER, S. Acne vulgaris. Lancet. v.379, n. 9813 p. 361-72 2012.

\section{Como citar este artigo (Formato ABNT):}

PEREIRA, Wesley G. O.; DAMASCENA, Rodrigo S. Avaliação dos potenciais efeitos adversos em pacientes em uso de Isotretinoína Oral para o tratamento de Acne Vulgar: Uma Revisão Bibliográfica. Id on Line Revista Multidisciplinar e de Psicologia, Abril de 2017, vol.11, n.35, p.42-55 . ISSN: 1981-1179. 